\title{
Changes in the Sequence of Eruption of Permanent Teeth; Correlation between Chronological and Dental Age and Effects of Body Mass Index of 5-15-year-old Schoolchildren
}

\author{
Aminah S Khan ${ }^{1}$, Priya Nagar ${ }^{2}$, Parul Singh ${ }^{3}$, Monali Bharti ${ }^{4}$
}

\begin{abstract}
Aim: To determine the changes in the sequence and age of eruption of permanent teeth in 5-15-year-old schoolchildren, correlating their dental and chronological age.

Materials and methods: A total of 1,477 schoolchildren aged between 5 years and 15 years were examined for the eruption timing, body mass index (BMI), and other oral findings. Dental age was calculated for $10 \%$ of the total sample using the Willem's method from their ortho-pento graphs (OPGs) and correlated with their chronological age.

Results: The maxillary teeth erupted earlier than mandibular teeth. Males were found to mature earlier than females. The sequence of eruption observed was: males (maxilla) 1-6-2-4-3-5-7 and (mandible) 1-6-2-3-4-5-7; females (maxilla) 6-1-2-4-3-5-7 and (mandible) 1-6-2-3-4-5-7. The chronological age and the dental age were found to be different in the age range of 9-10 years female; 10-11 years male; and in 13-14 years both male and female. Also when the dental age was correlated with the BMI, the dental age of obese children in 5-6 years and underweight children in 10-11 years were found to be far ahead of their actual chronological age.

Conclusion: This study opens an expected door for a large sample size to be tested in various local populations with different ethnicity and race as there can be changing trend in the eruption pattern.

Clinical significance: Changing trends in the sequence and age of eruption of the permanent teeth definitely need to be looked into. As this change, if firmly established in future, can help pedodontist in better planning of space management, interceptive as well as full-mouth orthodontic treatment which largely depends on this sequence being true in most of the cases.

Keywords: Body mass index, Changing trends, Chronological age, Dental age, Eruption sequence, Willems method.

International Journal of Clinical Pediatric Dentistry (2020): 10.5005/jp-journals-10005-1797
\end{abstract}

\section{INTRODUCTION}

A child in his process to become an adult passes through a complex system of biological development of varied origin, intensity, and importance such as skeletal growth, calcification, and eruption of teeth. Tooth is synchronous with growth and development of the craniofacial complex, and marks as an important milestone in a child's development. ${ }^{1}$

Average time of emergence of permanent teeth is important to be established for diagnosis, orthodontic treatment planning, and preventive dentistry procedures.

Individuals with variations like ethnicity, race, gene pool, hormonal factors, geographical area, gender, social status, nutrition, and growth tend to exhibit difference in eruption patterns and timing of eruption of individual teeth. The normal tooth eruption patterns that were recorded for a Western society cannot be applied to an Indian scenario. The literature related to eruption age of Indian children appears to be meager.

Some of the earliest studies are of Shourie ${ }^{2}$ who reported the tooth eruption age for schoolchildren in the age group of 6-21 years. Kaul, Saini, and Saxena in 1975 reported the eruption ages for permanent teeth of North Indian (Chandigarh) children. ${ }^{3}$ And the classic study by Amrit Tewari and Harpinder Singh Chawla in $1978^{4}$ among North Indian children marked a greater significance in the study of sequence and eruption age of permanent teeth, which is still being followed as the gold standard.

Eruption of the teeth was found to be positively related to somatic growth (height and weight) of individuals. Height and
${ }^{1-4}$ Department of Pedodontics and Preventive Dentistry, Krishnadevaraya College of Dental Science, Bengaluru, Karnataka, India

Corresponding Author: Aminah S Khan, Department of Pedodontics and Preventive Dentistry, Krishnadevaraya College of Dental Science, Bengaluru, Karnataka, India, Phone: +974 7006 2867, e-mail: aminah. thedento@yahoo.com

How to cite this article: Khan AS, Nagar $\mathrm{P}$, Singh $\mathrm{P}$, et al. Changes in the Sequence of Eruption of Permanent Teeth; Correlation between Chronological and Dental Age and Effects of Body Mass Index of 5-15-year-old Schoolchildren. Int J Clin Pediatr Dent 2020;13(4): 368-380.

Source of support: Nil

Conflict of interest: None

weight are the physical markers of growth and development that are utilized the most in diagnostic procedures and also in evaluation of development in growth. Because of the changes in the environment leading to increasing trend of sedentary lifestyle and a high consumption of energy-rich food and drinks resulted in conditions like overweight and obesity in children. However, with the changing trends, variations in the sequence and eruption age need to be reanalyzed and should lead to developing a new standard table for tooth eruption, which is personalized to the local citizens in which they are to be applied. 
In the present study, an effort has been made to establish the new norms of the age and the eruption sequence of permanent teeth for schoolchildren from 5 to 15 years by recording individual sequences of tooth emergence, which will approximate the prevalence of the different sequences in a population and can compare them with those already existing in the literature.

This descriptive cross-sectional survey was conducted on the 1,404 government, public, and private primary and secondary schoolchildren of 5-15 years from North Bengaluru. Prior to the field study an appropriate written consent was obtained from the head of the institutions and parents either in English or in the local language.

\section{Inclusion Criteria}

- Healthy children 5-15 years of age of Indian decent.

- Children who are healthy both physically and mentally.

- Children with correct records for their age obtained from school.

- A tooth was considered to be erupted when any part of it has pierced the gingiva and could be touched and seen.

- Ortho-pento graphs (OPGs) without any distortions.

\section{Exclusion Criteria}

- Children with history of chronic infectious, nutritional, or endocrine diseases, recognized syndromes, and developmental disturbances such as cleft lip and palates or severe medical illness.

- Third molars.

Ethical approval was obtained from the ethical board committee of our institution.

Prior to the field survey, research assistants were trained in data collection of government primary school. They were trained to measure height and weight of the children. However, the eruption of teeth was examined by the main examiner only.

\section{Data Collection and Recording}

All the children were inspected by the main examiner with the help of a trained assistant. A maximum of 50 children per day were examined over a period of 3 months. Examination was done using a mouth mirror and probe in adequate natural illumination. Each tooth was scored based on emergence stages by Pahkala et al. ${ }^{5}$ depending on the level of its eruption clinically and recorded on individuals pro forma.

The child's BMI was calculated. The weight was noted in kilograms up to two decimal point using a digital weighing scale. The height was recorded from the heel to the uppermost part of the head using a wall mountable stature meter in centimeters and corrected to nearest decimal point. Other observations such as the profile of the patient and crowding in relation to upper and lower arch were also recorded.

\section{Data Analysis}

The data were analyzed using the Statistical Package for Social Science Inc. (SPSS, version 18 for Windows, Chicago, Illinois, USA). Student's $t$-test for paired observations was used to check for systematic errors in anthropometric measurements.

\section{Dental Age Calculation}

The chronological age was obtained from the actual date of birth either as per school records and further was authenticated by interrogating the child. Later from the date of birth, age was calculated in terms of years and month. And for the dental age estimation, out of 1,404 schoolchildren $10 \%$ of the sample, i.e., 140 children, were randomly selected from both the gender and divided into ten groups. Orthopantomogram was taken using the Kodak Carestream 90003D machine. The application Trophy Dicom 6.4 was used to enter the details of the patient such as the OPD number, name, age, sex, and date of birth in the HP Pentium 4 processor 4600 workstation. These details were also copied in the proforma for each individual, including date of birth and date of OPG for all of them and the dental age was estimated using the Willems method. ${ }^{6}$ The OPGs were transferred to Sony CD-R 700 $M B$ to view each of the digital radiograph to score them. The data were arranged in the ascending order of ages. Staging was done using the Demirjian's tooth development chart for all the teeth present in the left lower quadrant denoted as 31, 32, 33, 34, 35, 36, 37 excluding the third molars.

Later on, these stages were scored by a blinded examiner with no prior knowledge of the age of the individual.

The correlation of the two was compared in terms of mean absolute error (MAE) between the estimated and actual age. The percentile was calculated by the percentage of confidence interval.

A total of 1,477 children aged 5-15 years were consecutively selected for the study (Table 1). The overall mean age of the children was found to be 10.09 years (boys: 9.87; girls: 10.33). Generally, the mean eruption times for boys was found to be lower as compared to girls.

The mean eruption age of males (Table 2).

\section{Maxillary Teeth}

The central incisor erupted at the mean age of 8.13 years and 8.21 years for 11 and 21, respectively; laterals erupted at 10.34 years and 10.26 years for 12 and 22; cuspids at 12.16 years and 12.10 years for 13 and 23; first bicuspids at 11.60 years and 11.69 years for 14 and 24, respectively; second bicuspids were found to erupt at the mean age of 12.22 years for 15 and 12.11 years for 25 . The mean eruption age of first molar was 8.17 years and 8.40 years for 16 and 26, respectively. And for second molar the mean eruption age was found to be 12.99 years and 12.98 years for 17 and 27, respectively.

\section{Mandibular Teeth}

The central incisors 31, 41 erupted at 7.168 years and 7.13 years, respectively. The lateral incisors 32, 42 erupted at the mean age of 9.08 years and 9.18 years, respectively. The canines 33,43 erupted at the mean age of 11.80 years and 11.77 years, respectively. The mean eruption age was 12.04 years and 11.99 years, for first bicuspids. And the second bicuspids erupted at the mean age of 12.18 years and 12.17 years. The first molars 16, 26 erupted at about 8.16 years and 8.19 years. And the second molars at the mean age of 12.64 years and 12.61 years.

The mean eruption age of females (Table 2).

Table 1: The frequency distribution of gender among the study population

\begin{tabular}{lcc}
\hline & Frequency & Percent \\
\hline Male & 770 & 52.1 \\
Female & 707 & 47.9 \\
Total & 1477 & 100.0 \\
\hline
\end{tabular}

Out of the total of $100 \%$, male includes $52.1 \%$ and female includes $47.9 \%$ 
Changes in the Sequence of Eruption of Permanent Teeth

Table 2: The frequency distribution of number of cases, mean, median, SD, and $p$ value of tooth eruption age (years) of boys and girls according to tooth types

\begin{tabular}{|c|c|c|c|c|c|c|c|c|c|}
\hline Teeth & & $N$ & $\begin{array}{l}\text { Mean (age in } \\
\text { months) }\end{array}$ & $\begin{array}{l}\text { Mean (age in } \\
\text { years) }\end{array}$ & $S D$ & Min. & Max. & tvalue & $p$ value \\
\hline \multirow[t]{2}{*}{11} & Male & 63 & 97.59 & 8.13 & 12.941 & 55 & 137 & 0.041 & 0.841 \\
\hline & Female & 69 & 98.09 & 8.17 & 15.310 & 78 & 147 & & \\
\hline \multirow[t]{2}{*}{12} & Male & 140 & 124.09 & 10.14 & 20.438 & 88 & 180 & 1.360 & 0.244 \\
\hline & Female & 186 & 126.88 & 10.57 & 22.050 & 73 & 180 & & \\
\hline \multirow[t]{2}{*}{13} & Male & 102 & 145.99 & 12.16 & 14.838 & 110 & 180 & 0.317 & 0.574 \\
\hline & Female & 129 & 144.88 & 12.07 & 14.815 & 106 & 176 & & \\
\hline \multirow[t]{2}{*}{14} & Male & 148 & 139.31 & 11.60 & 16.746 & 95 & 177 & 0.067 & 0.796 \\
\hline & Female & 152 & 138.83 & 11.56 & 15.526 & 92 & 180 & & \\
\hline \multirow[t]{2}{*}{15} & Male & 108 & 146.64 & 12.22 & 14.260 & 115 & 180 & 1.008 & 0.316 \\
\hline & Female & 119 & 148.55 & 12.37 & 14.324 & 109 & 180 & & \\
\hline \multirow[t]{2}{*}{16} & Male & 85 & 98.13 & 8.17 & 20.360 & 69 & 156 & 0.605 & 0.438 \\
\hline & Female & 73 & 95.63 & 7.96 & 19.879 & 63 & 169 & & \\
\hline \multirow[t]{2}{*}{17} & Male & 144 & 155.88 & 12.99 & 13.383 & 117 & 180 & 0.142 & 0.707 \\
\hline & Female & 181 & 156.48 & 13.04 & 14.958 & 109 & 180 & & \\
\hline \multirow[t]{2}{*}{21} & Male & 63 & 98.63 & 5.21 & 13.135 & 55 & 137 & 0.080 & 0.778 \\
\hline & Female & 62 & 97.92 & 8.16 & 15.153 & 72 & 147 & & \\
\hline \multirow[t]{2}{*}{22} & Male & 140 & 123.23 & 10.26 & 20.341 & 88 & 180 & 1.612 & 0.205 \\
\hline & Female & 194 & 126.24 & 10.52 & 22.080 & 73 & 180 & & \\
\hline \multirow[t]{2}{*}{23} & Male & 106 & 145.23 & 12.10 & 15.528 & 108 & 180 & 0.012 & 0.914 \\
\hline & Female & 138 & 145.01 & 12.08 & 14.845 & 106 & 180 & & \\
\hline \multirow[t]{2}{*}{24} & Male & 156 & 140.34 & 11.69 & 15.301 & 96 & 177 & 0.085 & 0.771 \\
\hline & Female & 151 & 139.82 & 11.65 & 15.863 & 92 & 180 & & \\
\hline \multirow[t]{2}{*}{25} & Male & 134 & 145.40 & 12.11 & 15.048 & 108 & 180 & 1.889 & 0.171 \\
\hline & Female & 128 & 147.95 & 12.32 & 14.978 & 109 & 180 & & \\
\hline \multirow[t]{2}{*}{26} & Male & 88 & 100.86 & 8.40 & 21.862 & 69 & 168 & 0.711 & 0.400 \\
\hline & Female & 66 & 97.91 & 8.15 & 21.050 & 63 & 169 & & \\
\hline \multirow[t]{2}{*}{27} & Male & 144 & 155.78 & 12.98 & 13.906 & 108 & 180 & 0.544 & 0.461 \\
\hline & Female & 180 & 156.97 & 13.08 & 14.932 & 109 & 180 & & \\
\hline \multirow[t]{2}{*}{31} & Male & 57 & 86.02 & 7.16 & 18.491 & 56 & 158 & 0.573 & 0.451 \\
\hline & Female & 46 & 88.41 & 7.36 & 12.130 & 63 & 124 & & \\
\hline \multirow[t]{2}{*}{32} & Male & 113 & 109.01 & 9.08 & 18.532 & 55 & 175 & 3.840 & 0.051 \\
\hline & Female & 92 & 104.22 & 8.68 & 15.928 & 79 & 147 & & \\
\hline \multirow[t]{2}{*}{33} & Male & 102 & 141.65 & 11.80 & 14.626 & 100 & 177 & 0.993 & 0.320 \\
\hline & Female & 113 & 139.63 & 11.63 & 15.011 & 99 & 173 & & \\
\hline \multirow[t]{2}{*}{34} & Male & 172 & 144.59 & 12.04 & 16.757 & 92 & 180 & 0.924 & 0.337 \\
\hline & Female & 186 & 142.96 & 11.91 & 15.335 & 99 & 180 & & \\
\hline \multirow[t]{2}{*}{35} & Male & 113 & 146.20 & 12.18 & 15.340 & 100 & 180 & 0.002 & 0.965 \\
\hline & Female & 135 & 146.28 & 12.19 & 13.004 & 108 & 180 & & \\
\hline \multirow[t]{2}{*}{36} & Male & 188 & 97.93 & 8.16 & 20.706 & 56 & 151 & 3.658 & 0.057 \\
\hline & Female & 152 & 102.57 & 8.54 & 24.021 & 62 & 173 & & \\
\hline 37 & Male & 166 & 151.75 & 12.64 & 15.944 & 96 & 180 & 1.326 & 0.250 \\
\hline & Female & 208 & 153.62 & 12.80 & 15.379 & 92 & 180 & & \\
\hline 41 & Male & 53 & 85.64 & 7.30 & 16.313 & 56 & 158 & 2.516 & 0.116 \\
\hline & Female & 45 & 90.58 & 7.54 & 14.132 & 67 & 137 & & \\
\hline 42 & Male & 122 & 110.22 & 9.18 & 19.692 & 55 & 175 & 0.869 & 0.352 \\
\hline & Female & 102 & 107.80 & 8.98 & 18.881 & 79 & 164 & & \\
\hline 43 & Male & 100 & 141.24 & 11.77 & 14.595 & 95 & 177 & 1.556 & 0.214 \\
\hline & Female & 122 & 138.70 & 11.55 & 15.529 & 100 & 173 & & \\
\hline
\end{tabular}


Contd...

\begin{tabular}{|c|c|c|c|c|c|c|c|c|c|}
\hline Teeth & & $N$ & $\begin{array}{l}\text { Mean (age in } \\
\text { months) }\end{array}$ & $\begin{array}{l}\text { Mean (age in } \\
\text { years) }\end{array}$ & $S D$ & Min. & Max. & tvalue & $p$ value \\
\hline \multirow[t]{2}{*}{44} & Male & 188 & 143.89 & 11.99 & 17.232 & 95 & 180 & 0.478 & 0.490 \\
\hline & Female & 175 & 142.71 & 11.89 & 14.920 & 108 & 180 & & \\
\hline \multirow[t]{2}{*}{45} & Male & 123 & 146.04 & 12.17 & 16.157 & 100 & 180 & 0.061 & 0.806 \\
\hline & Female & 138 & 145.59 & 12.13 & 13.125 & 115 & 180 & & \\
\hline \multirow[t]{2}{*}{46} & Male & 160 & 98.36 & 8.19 & 21.247 & 56 & 151 & 0.468 & 0.495 \\
\hline & Female & 132 & 100.11 & 8.34 & 22.575 & 62 & 149 & & \\
\hline \multirow[t]{2}{*}{47} & Male & 171 & 151.43 & 12.61 & 15.935 & 108 & 180 & 1.762 & 0.185 \\
\hline & Female & 203 & 153.54 & 12.79 & 14.761 & 116 & 180 & & \\
\hline
\end{tabular}

\section{Maxillary Teeth}

The central incisors 11, 21 erupted at 8.17 years and 8.16 years, respectively. The lateral incisors 12,22 erupted at the mean age of 10.57 years and 10.52 years, respectively. The cuspids 13,23 at the mean age of 12.07 years and 12.08 years were found to be erupted. The mean eruption age of first bicuspids 14, 24 observed was 11.56 and 11.65 years, respectively. And the mean age of eruption of second bicuspids was found to be 12.37 years and 12.32 years, respectively. The first molars 16, 26 were found to be erupted at the mean age of 7.96 years and 8.15 years, respectively. The second molars 17, 27 erupted at the mean age of 13.04 years and 13.08 years, respectively.

\section{Mandibular Teeth}

The central incisors 31, 41 erupted at 7.36 years and 7.54 years, respectively. It was found that lateral incisors erupted at the mean age of 8.68 years and 8.98 years. The cuspids $(33,43)$ erupted at the mean age of 11.63 years and 11.55 years, respectively. The first bicuspids erupted at the mean age of 11.91 years and 11.89 years. The second bicuspids $(35,45)$ erupted at the mean age of 12.19 years and 12.13 years. The mean eruption age of first molars was found to be 8.54 years and 8.34 years. And the second molars $(37,47)$ erupted at the mean age of 12.80 years and 12.79 years, respectively.

\section{Discussion}

Teeth are an important part of the dentomaxillofacial complex. They are the biological markers of maturity and they are an important milestone in an individual's life. ${ }^{7}$ The tooth eruption represent the final stage in teeth formation, in which the tooth migrates from the bone toward the oral cavity. The current study is a crosssectional study that is preferred to the longitudinal method, as it yields results that are a better representation of the population according to Dahlberg and Menegaz-Bock. ${ }^{8}$ In routine clinical practice, it has been observed that the timing of permanent tooth eruption varies greatly when compared with the standard table of chronology, as given by Logan and Kronfeld ${ }^{7}$ and modified by McCall and Schour ${ }^{9}$ in 1940. Studies have shown that people from different ethnic and racial groups not only show different variations in growth and development but also show difference in eruption pattern and timing of individual teeth. Since the evolution over a span of thousands of years, the human race has seen many changes in the food and oral hygiene habits, which influenced the eruption sequence of teeth as well.

Eruption age of permanent teeth of 1,510 schoolchildren of Chandigarh was studied by Amrit. ${ }^{4}$ Khan $^{10}$ studied the eruption age of permanent teeth among 4,370 Pakistani children and concluded that the right first molars of upper and lower jaws showed the minimum change in the eruption age. Second molars were observed to be the last tooth to emerge. All the mandible teeth, except the premolars, usually erupted earlier than maxillary teeth. Lakshmappa et al. ${ }^{11}$ studied the eruption age and patterns of eruption of permanent teeth of schoolchildren of India and found that the mean age of eruption obtained was strikingly comparable with those of other investigations in different populations across the world.

Moshkelgosha et al. ${ }^{12}$ observed variation in the eruption timing of the mandibular canine and first premolar teeth in children who had dental crowding. Poureslami et al. ${ }^{13}$ found that there was a significant correlation between eruption pattern of first primary and permanent teeth. Krishnan and Liza John ${ }^{14}$ found that canine preceded the second premolar eruption. Also the first and second premolar erupted earlier in the maxilla than in the mandible.

The growth and development patterns cannot be universally applied owing to ethnic variations. The standards for tooth eruption patterns derived for a Western area cannot be applied to an Indian scenario. Hence, there is a need for a study that will generate local data. Studies have been conducted in Mangaluru, Mysore, whereas for North Bengaluru our study would be of great significance as it's the first study to be conducted and could be used as standards for this region as the sample size is moderately high. Tooth eruption age must be based upon a mean with wide latitude of variation for individual cases as suggested by Dahlberg and Menegaz-Bock. ${ }^{8}$

Despite the improvements in treatment modalities and use of high technological equipment used for contemporary pediatric orthodontics, not much effort has been made to advance preventive orthodontic services. Prediction of teeth eruption age would be useful in interceptive guidance of occlusion, i.e., serial extraction, especially to determine eventual extractions of deciduous teeth and timing of orthodontic treatment. If in a situation there is an interruption in the sequence of eruption maybe due to a slow-erupting upper adult canine, it can lead to formation of a malocclusion. The sequence of exfoliation of the lower deciduous canine and molars can lead to increased mandibular incisal crowding or self-correction during the late mixed dentition. Self-correction of crowding is not a frequent event, since about $89 \%$ of crowded dentition does not improve after 8-14 years of age and $37 \%$ of cases generally show an increase in mandibular crowding between 6 and 14 years of age. In a study by Krishnan. ${ }^{14}$ among North Kerala among 648 children, 131 subjects were found to have erupted canines in the mandibular arch with unerupted second premolars, 36 subjects had erupted second 
premolars with unerupted canines in maxilla. Also Cecere et al. ${ }^{15}$ had showed differences in the sequence of eruptions in the maxillary quadrants such as 6-1-2-3-4-7-5 in about $27.2 \%$, whereas in the mandibular quadrant, most of them had sequences starting with 1-6-2. However, there are known sequences, for example, 5-6-1-42-7-3 and 4-6-1-5-2-3-7, that are very unlikely in a clinical situation and have a very low estimated prevalence.

In this study, we had chosen a random sample among the government schools so that they all eat almost similar food and their nutrition is standardized. We had specifically chosen only North Bengaluru schools so that there is not much of changes in habits, food, and oral hygiene habits.

Our study shows (Table 2) overall early eruption of permanent teeth in males than in females, which was found to be in contrast with Hoffding et al., ${ }^{16}$ Magnusson, ${ }^{17}$ and Savara ${ }^{18}$ because of the changes in the quality of life, food habits, and oral hygiene habits over a period of years, which could be of a major influence to the eruption of teeth as well.

In our study, the mean eruption age of maxillary and mandibular central incisors was observed to be erupting earlier than the average age known. Significantly, they were found to erupt even before the eruption of first molars in both the maxillary and mandibular arch in both males and females except in the maxillary arch in females, which was been found to follow the standard pattern as given by Logan and Kronfeld. ${ }^{7}$

In the first transitional period, if the incisors erupt even before the first molars the prediction of incisor liability becomes easier at the early age, which would benefit the pedodontist in case if the arch is crowded and if it's indicated for any orthodontic interception. Also the Leeway space because of the second mesial shift can happen more appropriately and benefit the treatment planning. Also it is clear from our study that mandibular teeth erupted earlier than their maxillary counterparts with minor discrepancies in first premolar that erupts early in the maxillary arch.

This is in agreement with the studies of Lee et al. ${ }^{19}$ and Hoffding et al. ${ }^{16}$

The eruption age of homologous teeth on right and left was almost similar, with a maximum difference being a month. The noticeable difference in the eruption time is, however, obvious in opposing teeth of upper and lower jaws.

The sequence of eruption described in the standard eruption pattern by Logan and Kronfeld ${ }^{7}$ is 6-1-2-4-3-5-7 in maxilla and 6-12-3-4-7 in mandible. Whereas in our study (Table 2 ) the following sequence was observed in males.

\begin{tabular}{|l|l|l|l|l|l|l|l|l|}
\hline 1 & 6 & 2 & 4 & & 3 & 5 & & 7 \\
\hline & & & & & & & & \\
\hline 1 & 6 & 2 & & 3 & 4 & & 5 & 7 \\
\hline
\end{tabular}

And in females the following sequence was observed:

\begin{tabular}{|l|l|l|l|l|l|l|l|}
\hline 6 & 1 & & 2 & 4 & 3 & 5 & 7 \\
\hline & & & & & & & \\
\hline 1 & & 6 & 2 & 3 & 4 & 5 & 7 \\
\hline
\end{tabular}

The sequence of eruption of first molar and central incisor has interchanged. It is the central incisor that erupts first in both the maxillary and mandibular arch in boys, whereas among girls the maxillary first molar erupts before central incisor and in mandibular arch the sequence is central incisor and then the first molar, which has not been evidenced in any of the previous studies particularly in this ethnic group.

The first permanent tooth to erupt in the oral cavity both in males and females was mandibular central incisor, followed by maxillary central incisor in male and first molar in female. In males, the maxillary teeth have preceded the mandibular teeth in two pairs: the first bicuspid and the second bicuspid by 0.4 years and 0.01 years, respectively. The mandibular cuspids erupted far earlier than the maxillary cuspids by 0.38 years. Another interesting finding observed was that the lower cuspid erupted after the upper first bicuspid in males, while in females lower cuspid erupted earlier than the upper first bicuspid. The last tooth to erupt was the maxillary second molar in both males and females. In females, the maxillary first bicuspid erupted earlier than its mandibular counterpart whereas the mandibular second bicuspid erupted earlier than its upper counterpart. The sequence of eruption of mandibular teeth in females is in agreement with Lee et al. ${ }^{19}$ According to Knott, ${ }^{20}$ the fourth tooth to commonly erupt is the first premolar in the maxillary arch and the canine in the mandibular arch, which has been found to be followed in our study.

In our study, in about seven children the permanent teeth had begun to erupt even at about 4 years 5 months of age in boys, which might be the evidence of changing early eruption ages of permanent teeth, even though it was observed in an insignificant number in our study. In about 54 children at the age range of 5-6 years permanent teeth were found to be erupting with majority of mandibular incisors and the molars.

Another change was that mandibular molar erupted even at 4.6 years in few cases including boys and girls and maxillary central incisor at 4.5 years in one boy. Maxillary molars were not present even at 9 years in two subjects, which might be probably because of impaction that was not known as we were unable to take radiographs for all the patients in a school setup. Also mandibular second molars were still unerupted in about four cases even at 14 years. And in one subject mandibular second molar was found to be erupted as early as 8-9 years. As these finding were noted in very few inconsiderable subjects only, it cannot be generalized for the entire population under study.

However, these changes in the sequence of eruption would be of great significance to pedodontist for the treatment planning with regards to serial extraction, timing of expansion for a maxillary or mandibular arch if needed, planning about the space maintenance, flap excision associated with delayed eruption, orthodontic interception, growth modulation as in case of functional appliances, and also for the probable prediction of attack and progress of dental caries, which would help for the fluoride application and pit and fissure sealant application. According to the standard, the time it takes for the occlusion to settle according to Logan and Kronfled ${ }^{7}$ is about 13 years whereas according to our study even by the age of 12.6 years the occlusion settles. And for few children even at the age of 10 years the occlusion settles down. This acceleration in the pattern of eruption could be correlated to the anthropometric measurements of each individual's gender, the changing hormonal balance in young children, the ethnicity, the socioeconomic status, etc. These finding will be of greater significance in the field of pedodontics and orthodontics primarily and also for preventive dentistry procedures, archeological, anthropological, paleontological, and may have legal as well as forensic applications.

When we try to plot biological responses against their causal stimuli, they often form a sigmoid curve. Sigmoid relationships 
can be linearized by transformations such as probit. For most study systems, the probit (normal sigmoid) gives the most closely fitting result. Probit transformation also helps in determining the percentage of subjects in whom the tooth was present at specific levels. ${ }^{21}$ According to Heidmann, ${ }^{22}$ the probit analysis was the best method of analyzing tooth eruption than any other method. In this present study, probit was applied for the analysis of mean age of eruption of permanent teeth. In our study as given in Figure 1 wherein the $x$-axis is the age in years of the children and the $y$-axis is the probit values. Each probit graph (Figs 1 to 14) evidences a sigmoid curve with separate markings for male and female for each teeth of maxillary and mandibular arches. The graph basically interprets the probability of finding that specific teeth at the particular age for both males and females.

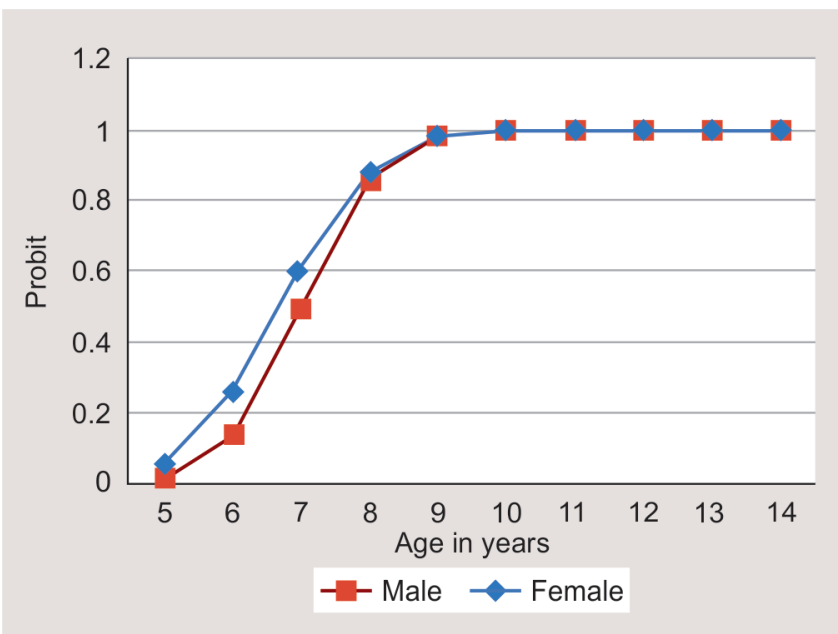

Fig. 1: Probit-transformed response for maxillary central incisor in males and females. The probability of finding a maxillary central incisor started even at 5 years. Until 9 years, the probability of finding the central incisor kept gradually increasing for both males and females in the study population. After which, from 10 years of age onward the probability of finding the tooth was the same for males and females

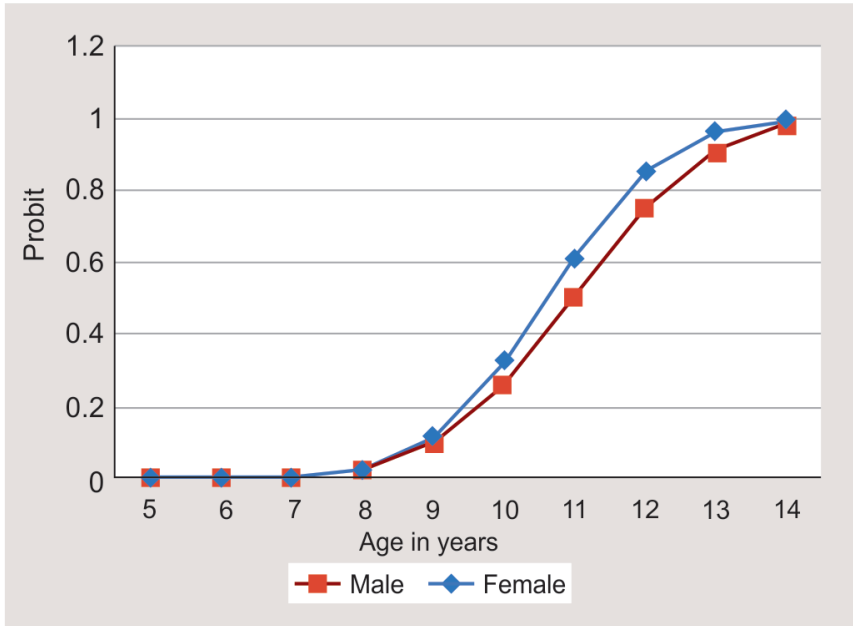

Fig. 3: Probit transformed response for maxillary canine in males and females. The probability of finding a maxillary canine started at $71 / 2$ years. After 8 years, the probability of finding the tooth follows a sigmoid curve until 14 years for both males and females
Estimation of dental age can be used as an important tool for treatment planning and can form a valuable asset during the developmental years for pediatricians, pedodontist, orthodontics, forensic medicine, pediatric endocrinology, orthopedics, etc. In the present study, we have correlated the chronological and the dental age using the Willems method ${ }^{6}$ of age estimation as it one of the modification of Demirjians method and found to be more appropriate among Indian population.

We are aware of the different categories of biological age, skeletal age, morphological age, secondary sexual character age, and dental age as told by Demirjian and Goldstein. ${ }^{23}$ However, significant individual variations have shown that the chronological age is a poor indicator of skeletal maturity as reported by Bhanat and Patel. ${ }^{24}$ Dental age assessment (DAA) has been found to be helpful

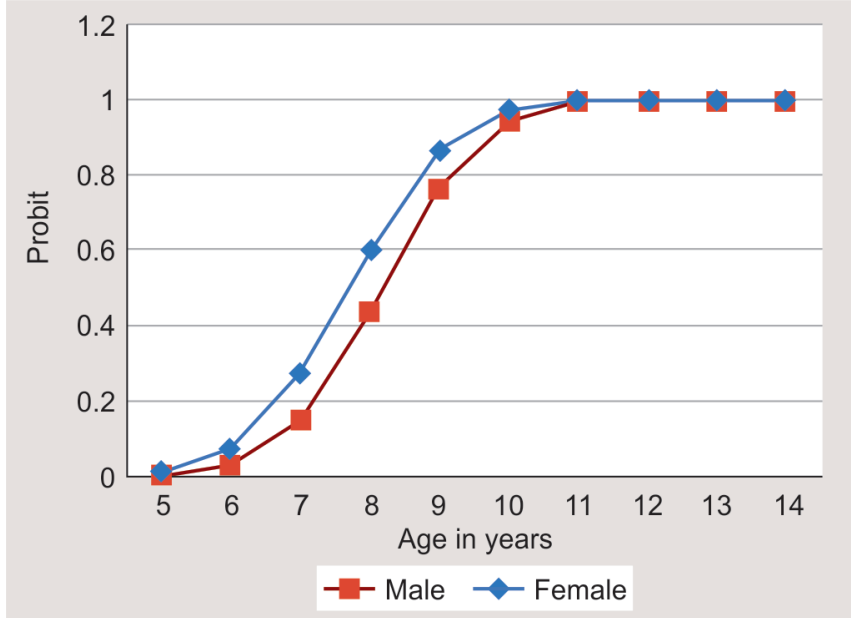

Fig. 2: Probit transformed response for maxillary lateral incisor in males and females. The probability of finding a maxillary lateral incisor started even at 5 years. Until 10 years the probability of finding the central incisor kept gradually increasing for both males and females in the study population. After which, from 11 years of age onward the probability of finding the tooth was the same for males and females

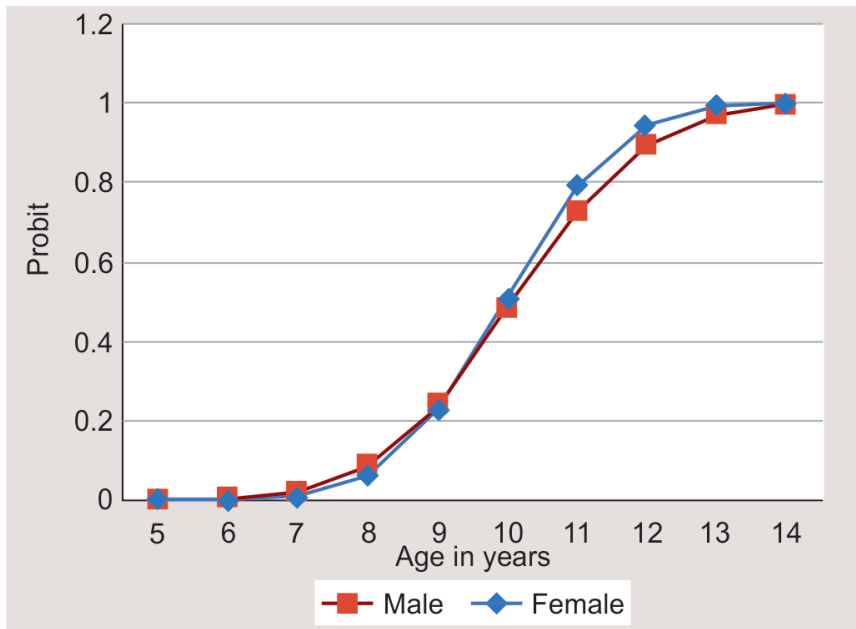

Fig. 4: Probit-transformed response for maxillary first premolar in males and females. The probability of finding a maxillary first premolar started at 7 years. From 7 to 13 years, the probability followed a sigmoid curve for both males and females intersecting at $9 \frac{1}{2}$ years 


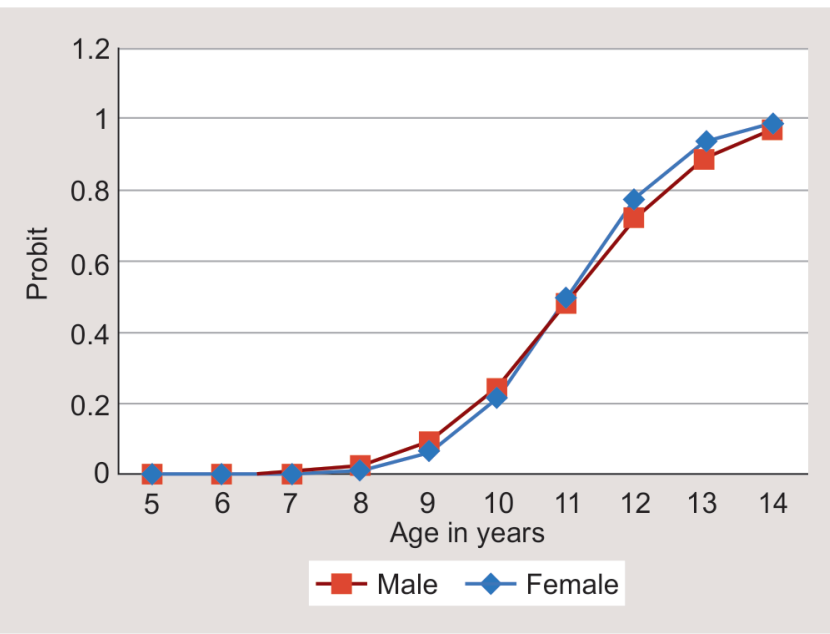

Fig. 5: Probit-transformed response for maxillary second premolar in males and females. The probability of finding a maxillary second premolar started at 8 years. From 8 years till 14 years, the probability of finding the tooth follows a sigmoid curve for both males and females intersecting at $10 \frac{1}{2}$ years

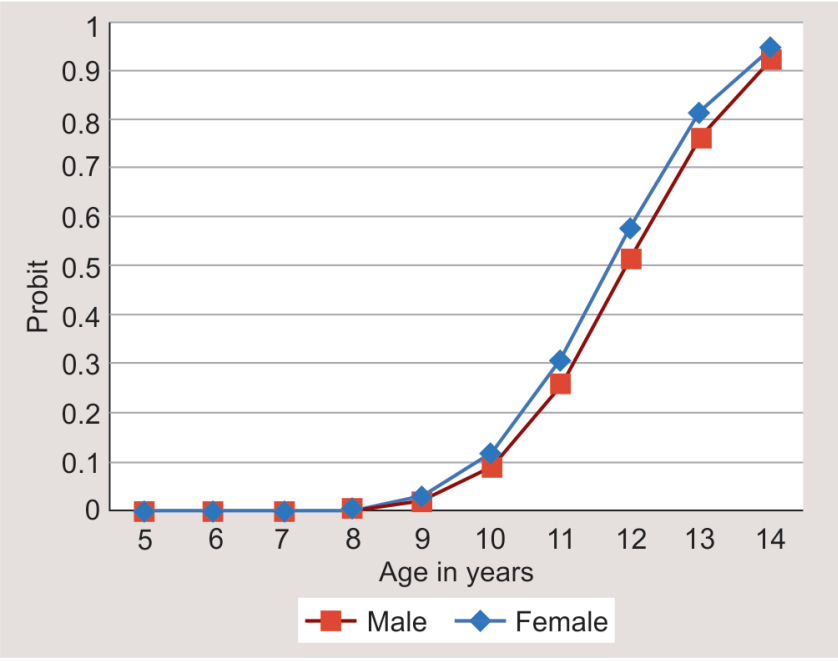

Fig. 7: Probit-transformed response for maxillary second molar in males and females. The probability of finding a maxillary second molar started after 8 years. From 9 to 14 years, the probability follows a sigmoid curve for both males and females

in decision making by the pediatric dentists and orthodontists in planning and timing treatment, and selecting the appropriate orthodontic appliance. ${ }^{24}$ It is found that by starting the treatment at the appropriate age, i.e., at the growth stage (pubertal growth spurt), it can help achieve ideal correction of skeletal discrepancies, optimal use of extraoral tractions, and functional appliances.

There is full accordance in literature that the method where DA estimation is relying on the evaluation of the mineralization and growth stages of the teeth, there seems to be scarcely affected by local and systemic factors, but are dependent on the genetics of the populations as they show an ethnic variability. Different methods are available for estimating the DA: Nolla's, ${ }^{25}$ Haavikko's, ${ }^{26}$ Demirjian's, ${ }^{23}$ and the modified Demirjian method by Willems et al. ${ }^{6}$ So as to quantify continuous process starting from first traces of cusps mineralization until root apex closure, Demirjian et al. had divided tooth formation into eight stages. ${ }^{23}$ In 2001, Willems

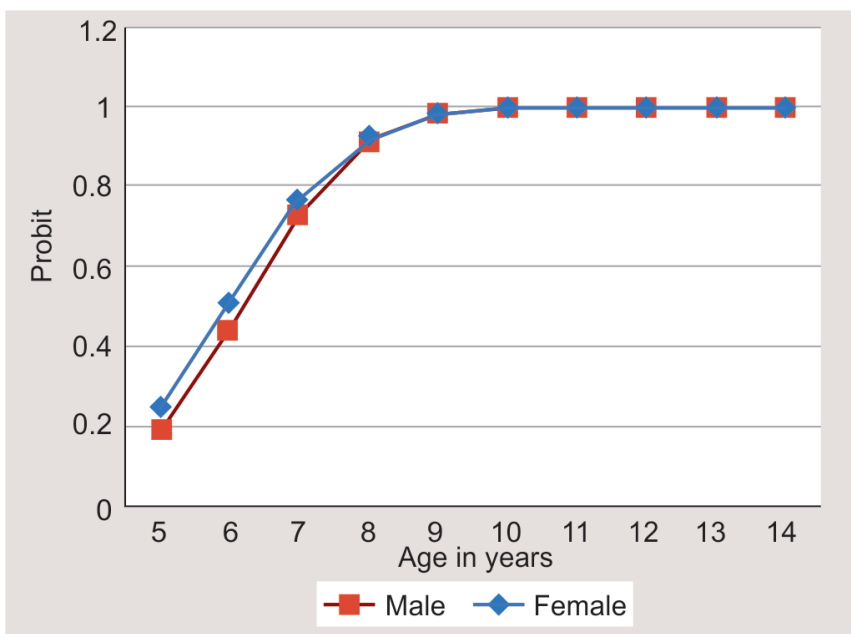

Fig. 6: Probit-transformed response for maxillary first molar in males and females. The probability of finding a maxillary first molar started even at 5 years. From 5 to 9 years, the probability gradually increases for both males and females. After 9 years, it is completed erupted

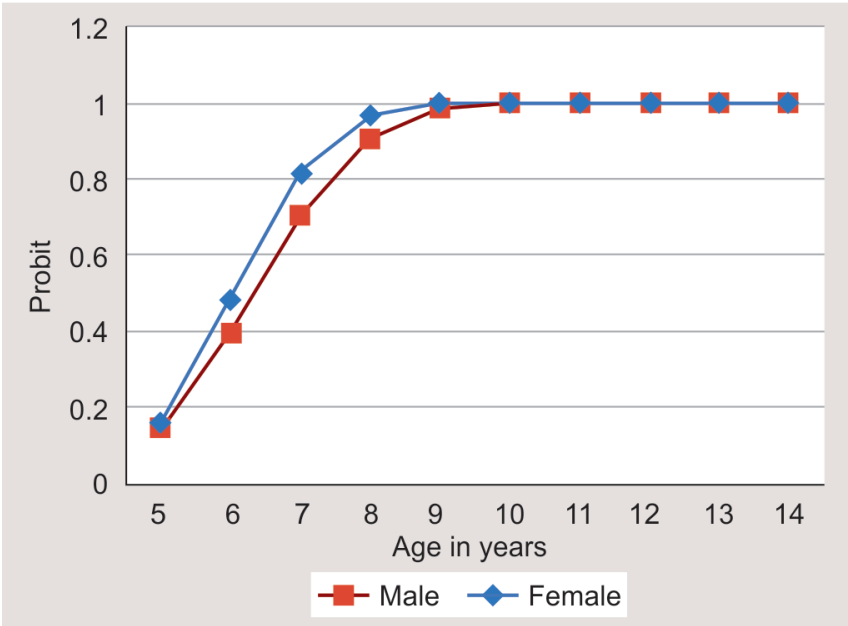

Fig. 8: Probit-transformed response for mandibular central incisors in males and females. The probability of finding a mandibular central incisor started even at 5 years. Until 9 years, the probability of finding the central incisor kept gradually increasing for both males and females in the study population. After which, it was completely erupted

et al. ${ }^{6}$ evaluated the accuracy of the Demirjian method in Belgian Caucasian population and modified the scoring system when a significant overestimation was reported. This modification has been evaluated among various communities and has been reported to be more accurate compared with the original method. As this method has also been tested in South Indian children of 6-16 years of age and found significant relation between estimated DA and CA, thus providing an insight in using the Willems ${ }^{6}$ method in our study.

In our study (Table 3 ), the dental age after estimation was correlated with the chronological age using the paired $t$-test, which shows that there was statistical significance in the age range of 9-10 years in female; 10-11 years in male; and in 13-14 years in both male and female. This might be because probably in 9-11 years of age range that the leeway space shift occurs replacing the deciduous first molar, second molar, and canine by the succedaneous teeth canine, first and the second premolar. Also in 13-14 years the 


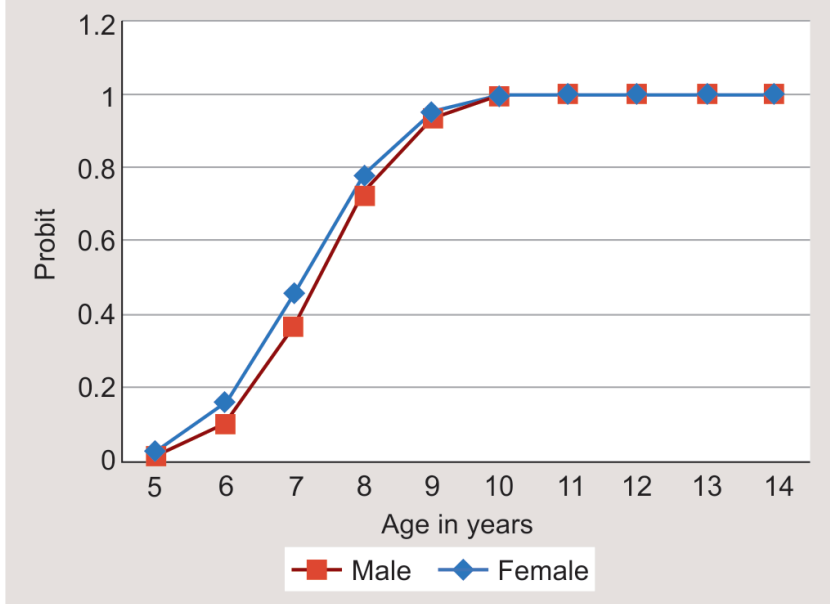

Fig. 9: Probit-transformed response for mandibular lateral incisors in males and females. The probability of finding a mandibular lateral incisor started even at 5 years. From then, it followed a sigmoid pattern until 10 years for both males and females after which it was completely erupted

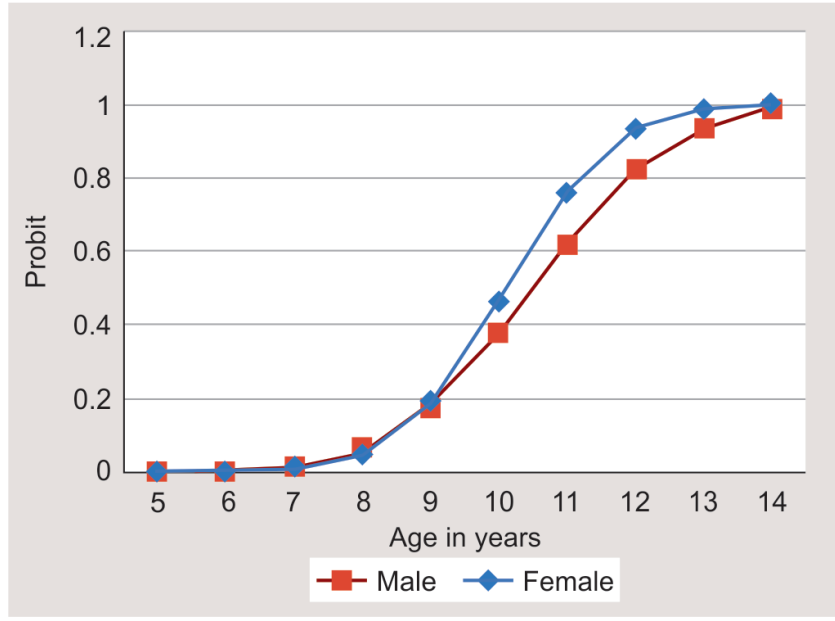

Fig. 11: Probit-transformed response for mandibular first premolar in males and females. The probability of finding a mandibular first premolar started at 7 years. After 7 years, the probability of finding the tooth follows a sigmoid curve until 14 years for both males and females

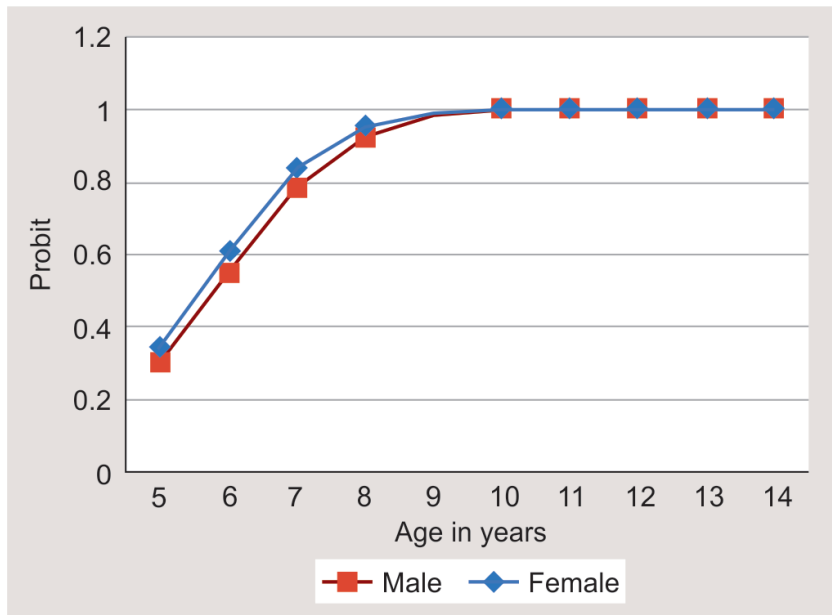

Fig. 13: Probit-transformed response for mandibular first molar in males and females. The probability of finding a mandibular first molar started at 5 years and then gradually increased till 10 years for both males and females. After 10 years, it was completely erupted

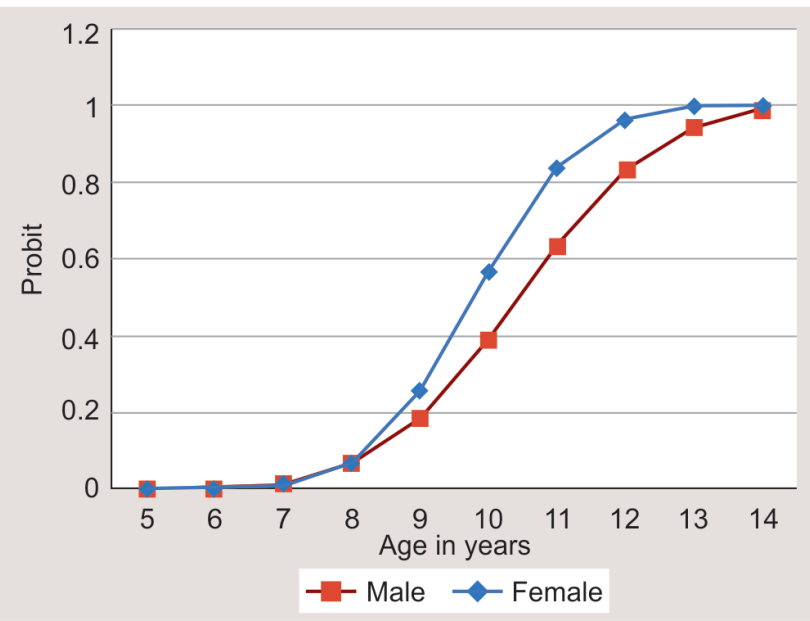

Fig. 10: Probit-transformed response for mandibular canine in males and females. The probability of finding a mandibular canine started at 7 years. After 7 years, the probability of finding the tooth follows a sigmoid curve until 14 years for both males and females

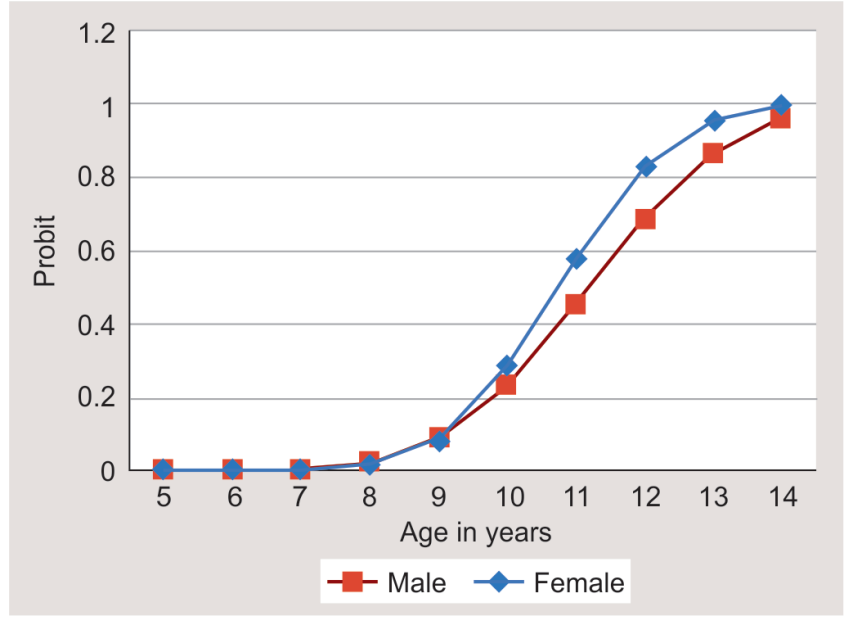

Fig. 12: Probit-transformed response for mandibular second premolar in males and females. The probability of finding a mandibular second premolar started at 8 years. After 8 years, the probability of finding the tooth follows a sigmoid curve until 14 years for both males and females

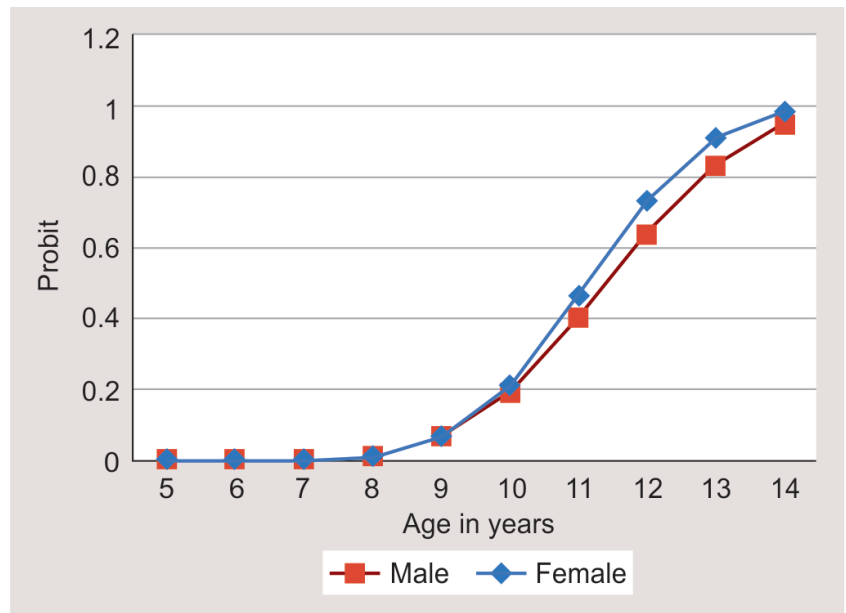

Fig. 14: Probit-transformed response for mandibular second molar in males and females. The probability of finding a mandibular second molar started at 8 years and then it followed a sigmoid pattern until 14 years for both males and females 
Table 3: Correlation between chronological age and dental age using paired $t$-test

\begin{tabular}{|c|c|c|c|c|c|c|c|c|c|}
\hline Age & Gender & & $N$ & Mean & $S D$ & Mean diff. & $S D$ & tvalue & $p$ value \\
\hline \multirow[t]{4}{*}{$5-6$ years } & Male & Age in months & 3 & 67.33 & 6.429 & -1.0 & 9.849 & -0.176 & 0.877 \\
\hline & & Dental age (months) & 3 & 68.33 & 11.150 & & & & \\
\hline & Female & Age in months & 5 & 67.00 & 4.000 & -10.2 & 18.404 & -1.239 & 0.283 \\
\hline & & Dental age (months) & 5 & 77.20 & 15.320 & & & & \\
\hline \multirow[t]{4}{*}{$6-7$ years } & Male & Age in months & 7 & 76.86 & 2.478 & 2.0 & 11.790 & 0.449 & 0.669 \\
\hline & & Dental age (months) & 7 & 74.86 & 13.384 & & & & \\
\hline & Female & Age in months & 7 & 77.29 & 2.628 & -31.3 & 30.516 & -2.712 & 0.035 \\
\hline & & Dental age (months) & 7 & 108.57 & 28.768 & & & & \\
\hline \multirow[t]{4}{*}{$7-8$ years } & Male & Age in months & 7 & 90.71 & 3.773 & -4.4 & 26.513 & -0.442 & 0.674 \\
\hline & & Dental age (months) & 7 & 95.14 & 24.990 & & & & \\
\hline & Female & Age in months & 6 & 88.17 & 2.483 & -2.7 & 15.371 & -0.425 & 0.689 \\
\hline & & Dental age (months) & 6 & 90.83 & 14.593 & & & & \\
\hline \multirow[t]{4}{*}{$8-9$ years } & Male & Age in months & 3 & 103.00 & 4.359 & -3.7 & 14.364 & -0.442 & 0.702 \\
\hline & & Dental age (months) & 3 & 106.67 & 12.503 & & & & \\
\hline & Female & Age in months & 7 & 106.14 & 1.952 & 8.6 & 17.338 & 1.308 & 0.239 \\
\hline & & Dental age (months) & 7 & 97.57 & 18.274 & & & & \\
\hline \multirow[t]{4}{*}{$9-10$ years } & Male & Age in months & 8 & 115.63 & 4.207 & 0.3 & 26.494 & 0.027 & 0.979 \\
\hline & & Dental age (months) & 8 & 115.38 & 24.669 & & & & \\
\hline & Female & Age in months & 11 & 114.27 & 3.036 & 14.4 & 20.714 & 2.300 & 0.044 \\
\hline & & Dental age (months) & 11 & 99.91 & 21.356 & & & & \\
\hline \multirow[t]{4}{*}{$10-11$ years } & Male & Age in months & 10 & 125.90 & 3.725 & 11.2 & 13.506 & 2.622 & 0.028 \\
\hline & & Dental age(months) & 10 & 114.70 & 13.889 & & & & \\
\hline & Female & Age in Months & 4 & 125.50 & 3.697 & 19.0 & 18.619 & 2.041 & 0.134 \\
\hline & & Dental age(months) & 4 & 106.50 & 18.628 & & & & \\
\hline \multirow[t]{4}{*}{$11-12$ years } & Male & Age in months & 6 & 138.50 & 3.937 & 6.2 & 17.815 & 0.848 & 0.435 \\
\hline & & Dental age (months) & 6 & 132.33 & 17.084 & & & & \\
\hline & Female & Age in months & 7 & 138.00 & 3.055 & 5.0 & 21.649 & 0.611 & 0.564 \\
\hline & & Dental age (months) & 7 & 133.00 & 19.287 & & & & \\
\hline \multirow[t]{4}{*}{$12-13$ years } & Male & Age in months & 10 & 152.60 & 2.413 & 16.1 & 33.811 & 1.506 & 0.166 \\
\hline & & Dental age (months) & 10 & 136.50 & 35.037 & & & & \\
\hline & Female & Age in months & 12 & 152.25 & 3.019 & 5.3 & 24.005 & 0.770 & 0.458 \\
\hline & & Dental age(months) & 12 & 146.92 & 24.637 & & & & \\
\hline \multirow[t]{4}{*}{$13-14$ years } & Male & Age in months & 7 & 161.14 & 2.545 & 17.0 & 17.711 & 2.540 & 0.044 \\
\hline & & Dental age (months) & 7 & 144.14 & 17.373 & & & & \\
\hline & Female & Age in months & 6 & 160.83 & 2.639 & 17.2 & 35.290 & 1.192 & 0.287 \\
\hline & & Dental age (months) & 6 & 143.67 & 34.938 & & & & \\
\hline \multirow[t]{4}{*}{$14-15$ years } & Male & Age in months & 3 & 174.00 & 5.292 & 28.7 & 14.572 & 3.407 & 0.076 \\
\hline & & Dental age (months) & 3 & 145.33 & 13.051 & & & & \\
\hline & Female & Age in months & 4 & 173.50 & 4.359 & 19.3 & 14.818 & 2.598 & 0.081 \\
\hline & & Dental age (months) & 4 & 154.25 & 12.816 & & & & \\
\hline
\end{tabular}

Statistical significance in the age range of 9-10 years female, 10-11 years male, and in 13-14 years both male and female with $p$ value $<0.05$

difference between dental age and chronological age is statistically significant as the occlusion settles at a much earlier age these days.

Based on the partial correlation analysis (Table 4), we observed that the average tooth eruption times were related to child BMI, which was statistically significant in the obese category. Among the various children, Khan $^{10}$ had observed that well-nourished children showed early tooth eruption. Also he observed that the eruption time of different teeth was either directly or indirectly related to the BMI, except for tooth 32. In which case the eruption times were found generally inversely related to the BMI.

The reason for the differences in tooth eruption age between boys and girls is poorly understood. It is understood that the earlier onset of the permanent dentition is part of the different sexual maturity of both sexes at a given age. In our study, the CDC growth charts were taken for assessing the BMI in girls and boys separately. Among the study population, majority of the children (55.1\% of the entire population) under study fell in the healthy weight category (Table 4). About $32.6 \%$ of them were underweight. About $6.4 \%$ were found to be overweight. And $5.4 \%$ were obese. The BMI showed statistical significance in the age ranges of 6-7 years and 14-15 years of boys and girls, i.e., the BMI of the children with these age ranges was comparatively variable than the other age groups. In our study when the dental age, chronological age, and the BMI were correlated (Table 5), there was found to be a 
Table 4: Frequency distribution of BMI among different age groups segregated by gender using paired $t$-test

\begin{tabular}{|c|c|c|c|c|c|c|c|c|}
\hline \multirow[b]{2}{*}{ Age } & & \multicolumn{4}{|c|}{$B M I$} & \multirow[b]{2}{*}{ Total } & \multirow[b]{2}{*}{$\chi^{2}$ value } & \multirow[b]{2}{*}{$p$ value } \\
\hline & & Underweight & Normal & Obese & Overweight & & & \\
\hline \multirow[t]{4}{*}{$5-6$ years } & Male & 15 & 38 & 12 & 3 & 68 & 3.866 & 0.276 \\
\hline & & $22.1 \%$ & $55.9 \%$ & $17.6 \%$ & $4.4 \%$ & $100.0 \%$ & & \\
\hline & Female & 21 & 30 & 16 & 7 & 74 & & \\
\hline & & $28.4 \%$ & $40.5 \%$ & $21.6 \%$ & $9.5 \%$ & $100.0 \%$ & & \\
\hline \multirow[t]{4}{*}{$6-7$ years } & Male & 49 & 45 & 2 & 0 & 96 & 9.921 & 0.019 \\
\hline & & $51.0 \%$ & $46.9 \%$ & $2.1 \%$ & $.0 \%$ & $100.0 \%$ & & \\
\hline & Female & 13 & 27 & 4 & 1 & 45 & & \\
\hline & & $28.9 \%$ & $60.0 \%$ & $8.9 \%$ & $2.2 \%$ & $100.0 \%$ & & \\
\hline \multirow[t]{4}{*}{$7-8$ years } & Male & 30 & 40 & 6 & 2 & 78 & 4.645 & 0.200 \\
\hline & & $38.5 \%$ & $51.3 \%$ & $7.7 \%$ & $2.6 \%$ & $100.0 \%$ & & \\
\hline & Female & 35 & 32 & 1 & 1 & 69 & & \\
\hline & & $50.7 \%$ & $46.4 \%$ & $1.4 \%$ & $1.4 \%$ & $100.0 \%$ & & \\
\hline \multirow[t]{4}{*}{$8-9$ years } & Male & 28 & 44 & 2 & 6 & 80 & 3.084 & 0.379 \\
\hline & & $35.0 \%$ & $55.0 \%$ & $2.5 \%$ & $7.5 \%$ & $100.0 \%$ & & \\
\hline & Female & 24 & 33 & 6 & 6 & 69 & & \\
\hline & & $34.8 \%$ & $47.8 \%$ & $8.7 \%$ & $8.7 \%$ & $100.0 \%$ & & \\
\hline \multirow[t]{4}{*}{ 9-10 years } & Male & 31 & 42 & 2 & 2 & 77 & 4.154 & 0.245 \\
\hline & & $40.3 \%$ & $54.5 \%$ & $2.6 \%$ & $2.6 \%$ & $100.0 \%$ & & \\
\hline & Female & 23 & 34 & 1 & 7 & 65 & & \\
\hline & & $35.4 \%$ & $52.3 \%$ & $1.5 \%$ & $10.8 \%$ & $100.0 \%$ & & \\
\hline \multirow[t]{4}{*}{$10-11$ years } & Male & 37 & 40 & 1 & 7 & 85 & 4.223 & 0.238 \\
\hline & & $43.5 \%$ & $47.1 \%$ & $1.2 \%$ & $8.2 \%$ & $100.0 \%$ & & \\
\hline & Female & 25 & 37 & 4 & 3 & 69 & & \\
\hline & & $36.2 \%$ & $53.6 \%$ & $5.8 \%$ & $4.3 \%$ & $100.0 \%$ & & \\
\hline \multirow[t]{4}{*}{$11-12$ years } & Male & 21 & 31 & 0 & 5 & 57 & 6.050 & 0.109 \\
\hline & & $36.8 \%$ & $54.4 \%$ & $.0 \%$ & $8.8 \%$ & $100.0 \%$ & & \\
\hline & Female & 21 & 57 & 5 & 6 & 89 & & \\
\hline & & $23.6 \%$ & $64.0 \%$ & $5.6 \%$ & $6.7 \%$ & $100.0 \%$ & & \\
\hline \multirow[t]{4}{*}{$12-13$ years } & Male & 34 & 60 & 2 & 8 & 104 & 4.903 & 0.179 \\
\hline & & $32.7 \%$ & $57.7 \%$ & $1.9 \%$ & $7.7 \%$ & $100.0 \%$ & & \\
\hline & Female & 17 & 44 & 5 & 9 & 75 & & \\
\hline & & $22.7 \%$ & $58.7 \%$ & $6.7 \%$ & $12.0 \%$ & $100.0 \%$ & & \\
\hline \multirow[t]{4}{*}{$13-14$ years } & Male & 20 & 40 & 2 & 6 & 68 & 2.000 & 0.572 \\
\hline & & $29.4 \%$ & $58.8 \%$ & $2.9 \%$ & $8.8 \%$ & $100.0 \%$ & & \\
\hline & Female & 16 & 41 & 5 & 8 & 70 & & \\
\hline & & $22.9 \%$ & $58.6 \%$ & $7.1 \%$ & $11.4 \%$ & $100.0 \%$ & & \\
\hline \multirow[t]{4}{*}{$14-15$ years } & Male & 18 & 31 & 2 & 6 & 57 & 19.146 & $<0.001$ \\
\hline & & $31.6 \%$ & $54.4 \%$ & $3.5 \%$ & $10.5 \%$ & $100.0 \%$ & & \\
\hline & Female & 4 & 68 & 2 & 8 & 82 & & \\
\hline & & $4.9 \%$ & $82.9 \%$ & $2.4 \%$ & $9.8 \%$ & $100.0 \%$ & & \\
\hline
\end{tabular}

The BMI showed statistical significance in the age ranges of 6-7 years and 14-15 years among both males and females

statistical significance among underweight children in the age range of 10-11 years. Also there was statistical significance among obese children in the age range of 5-6 years. The dental age was far ahead than the chronological age in both the cases, i.e., early eruption was observed. The crowding of lower anteriors was found to be more $34.1 \%$ in our study with a maximum of $46.1 \%$ at $10-11$ years (mixed dentition) wherein the second transitional movement takes place. In our study, subjects with the convex profile was found to be more common constituting $61.7 \%$ of the total sample having preferably class 1 malocclusion. This was in accordance with the study by Mallick et al., ${ }^{27}$ Raina et al., ${ }^{28}$ and Tak et al. ${ }^{29}$ And was in contrast to Shivkumar et al., ${ }^{30}$ which were also done among the children of Karnataka.

\section{Conclusion}

The growth and development patterns cannot be universally applied to the various ethnic variations. The standards for tooth 
Table 5: Correlation of dental age, chronological age, and the BMI

\begin{tabular}{|c|c|c|c|c|c|c|c|c|}
\hline Age & $B M I$ & & $N$ & Mean & $S D$ & Mean diff & SE of diff & $p$ value \\
\hline \multirow[t]{8}{*}{$5-6$ years } & Underweight & Dental age (months) & 89.00 & 3 & 7.550 & 21.67 & 6.960 & 0.090 \\
\hline & & Age (months) & 67.33 & 3 & 4.509 & & & \\
\hline & Normal & Dental age (months) & 69.00 & 2 & 7.071 & 7.50 & 3.500 & 0.278 \\
\hline & & Age (months) & 61.50 & 2 & 2.121 & & & \\
\hline & Obese & Dental age (months) & 62.00 & 3 & 2.646 & -8.67 & 1.333 & 0.023 \\
\hline & & Age (months) & 70.67 & 3 & 0.577 & & & \\
\hline & Overweight & Dental age (months) & & 0 & & & & \\
\hline & & Age (months) & & 0 & & & & \\
\hline \multirow[t]{8}{*}{$6-7$ years } & Underweight & Dental age (months) & 75.67 & 6 & 16.561 & -1.17 & 6.269 & 0.860 \\
\hline & & Age (months) & 76.83 & 6 & 2.563 & & & \\
\hline & Normal & Dental age (months) & 87.75 & 4 & 16.215 & 8.25 & 8.128 & 0.385 \\
\hline & & Age (months) & 79.50 & 4 & 1.000 & & & \\
\hline & Obese & Dental age (months) & 111.67 & 3 & 34.078 & 37.00 & 19.655 & 0.200 \\
\hline & & Age (months) & 74.67 & 3 & 0.577 & & & \\
\hline & Overweight & Dental age (months) & 144.00 & 1 & & & & \\
\hline & & Age (months) & 76.00 & 1 & & & & \\
\hline \multirow[t]{8}{*}{$7-8$ years } & Underweight & Dental age (months) & 88.33 & 6 & 12.144 & -0.33 & 5.251 & 0.952 \\
\hline & & Age (months) & 88.67 & 6 & 2.733 & & & \\
\hline & Normal & Dental age (months) & 88.00 & 4 & 11.576 & -5.00 & 5.672 & 0.443 \\
\hline & & Age (months) & 93.00 & 4 & 2.582 & & & \\
\hline & Obese & Dental age (months) & 109.67 & 3 & 36.529 & 23.00 & 21.127 & 0.390 \\
\hline & & Age (months) & 86.67 & 3 & 1.155 & & & \\
\hline & Overweight & Dental age (months) & & 0 & & & & \\
\hline & & Age (months) & & 0 & & & & \\
\hline \multirow[t]{8}{*}{$8-9$ years } & Underweight & Dental age (months) & 115.67 & 3 & 4.619 & 11.00 & 4.509 & 0.135 \\
\hline & & Age (months) & 104.67 & 3 & 3.215 & & & \\
\hline & Normal & Dental age (months) & 96.17 & 6 & 15.381 & -9.00 & 5.820 & 0.183 \\
\hline & & Age (months) & 105.17 & 6 & 3.371 & & & \\
\hline & Obese & Dental age (months) & 79.00 & 1 & & & & \\
\hline & & Age (months) & 107.00 & 1 & & & & \\
\hline & Overweight & Dental age (months) & & 0 & & & & \\
\hline & & Age (months) & & 0 & & & & \\
\hline \multirow[t]{8}{*}{$9-10$ years } & Underweight & Dental age (months) & 103.40 & 5 & 23.458 & -11.20 & 9.573 & 0.307 \\
\hline & & Age (months) & 114.60 & 5 & 4.879 & & & \\
\hline & Normal & Dental age (months) & 109.00 & 13 & 24.590 & -5.54 & 6.976 & 0.443 \\
\hline & & Age (months) & 114.54 & 13 & 2.904 & & & \\
\hline & Obese & Dental age (months) & & 0 & & & & \\
\hline & & Age (months) & & 0 & & & & \\
\hline & Overweight & Dental age (months) & 88.00 & 1 & & & & \\
\hline & & Age (months) & 120.00 & 1 & & & & \\
\hline \multirow[t]{8}{*}{ 10-11 years } & Underweight & Dental age (months) & 113.00 & 9 & 14.124 & -10.89 & 4.238 & 0.033 \\
\hline & & Age (months) & 123.89 & 9 & 2.147 & & & \\
\hline & Normal & Dental age (months) & 111.20 & 5 & 18.458 & -18.00 & 8.367 & 0.098 \\
\hline & & Age (months) & 129.20 & 5 & 3.114 & & & \\
\hline & Obese & Dental age (months) & & 0 & & & & \\
\hline & & Age (months) & & 0 & & & & \\
\hline & Overweight & Dental age (months) & & 0 & & & & \\
\hline & & Age (months) & & 0 & & & & \\
\hline \multirow[t]{2}{*}{$11-12$ years } & Underweight & Dental age (months) & 131.00 & 3 & 19.313 & -6.00 & 12.166 & 0.671 \\
\hline & & Age (months) & 137.00 & 3 & 2.646 & & & \\
\hline
\end{tabular}




\begin{tabular}{|c|c|c|c|c|c|c|c|c|}
\hline Age & $B M I$ & & $N$ & Mean & $S D$ & Mean diff & SE of diff & $p$ value \\
\hline & Normal & Dental age (months) & 134.33 & 9 & 18.775 & -4.44 & 6.904 & 0.538 \\
\hline & & Age (months) & 138.78 & 9 & 3.734 & & & \\
\hline & Obese & Dental age (months) & 123.00 & 1 & & & & \\
\hline & & Age (months) & 137.00 & 1 & & & & \\
\hline & Overweight & Dental age (months) & & 0 & & & & \\
\hline & & Age (months) & & 0 & & & & \\
\hline \multirow[t]{8}{*}{$12-13$ years } & Underweight & Dental age (months) & 144.60 & 5 & 38.501 & -6.40 & 16.024 & 0.710 \\
\hline & & Age (months) & 151.00 & 5 & 3.808 & & & \\
\hline & Normal & Dental age (months) & 137.69 & 13 & 28.271 & -14.92 & 7.704 & 0.077 \\
\hline & & Age (months) & 152.62 & 13 & 2.399 & & & \\
\hline & Obese & Dental age (months) & 127.00 & 1 & & & & \\
\hline & & Age (months) & 156.00 & 1 & & & & \\
\hline & Overweight & Dental age (months) & 162.67 & 3 & 22.546 & 10.00 & 12.423 & 0.505 \\
\hline & & Age (months) & 152.67 & 3 & 1.155 & & & \\
\hline \multirow[t]{8}{*}{$13-14$ years } & Underweight & Dental age (months) & 138.00 & 3 & 22.650 & -24.00 & 13.279 & 0.212 \\
\hline & & Age (months) & 162.00 & 3 & 2.646 & & & \\
\hline & Normal & Dental age (months) & 152.22 & 9 & 19.117 & -8.56 & 6.589 & 0.230 \\
\hline & & Age (months) & 160.78 & 9 & 2.635 & & & \\
\hline & Obese & Dental age (months) & & 0 & & & & \\
\hline & & Age (months) & & 0 & & & & \\
\hline & Overweight & Dental age (months) & 87.00 & 1 & & & & \\
\hline & & Age (months) & 160.00 & 1 & & & & \\
\hline \multirow[t]{8}{*}{$14-15$ years } & Underweight & Dental age (months) & 147.50 & 2 & 17.678 & -23.50 & 11.500 & 0.290 \\
\hline & & Age (months) & 171.00 & 2 & 1.414 & & & \\
\hline & Normal & Dental age (months) & 154.25 & 4 & 12.816 & -19.25 & 7.409 & 0.081 \\
\hline & & Age (months) & 173.50 & 4 & 4.359 & & & \\
\hline & Obese & Dental age (months) & & 0 & & & & \\
\hline & & Age (months) & & 0 & & & & \\
\hline & Overweight & Dental age (months) & 141.00 & 1 & & & & \\
\hline & & Age (months) & 180.00 & 1 & & & & \\
\hline
\end{tabular}

Statistical significance among underweight children was observed in the age range of 10-11 years and among obese children in the age range of 5-6 years $(p<0.05)$

eruption patterns derived for a Western population cannot be applied to an Indian scenario. Hence, in our present study done on 1,477 schoolchildren, a moderately high sample size can be significantly used as a standard as for the North Bengaluru population but to establish new standards in the sequence and timing of eruption of various teeth there is a need to reevaluate by picking up a larger population.

\section{Clinical Significance}

This study opens an expected door for a large sample size to be tested in various local populations with different ethnicity and race. As probably it's time we need to get a check into the changing trend in the eruption pattern. As this change, if firmly established in future can help in prevention, better planning of interceptive, as well as full-mouth orthodontic treatment, which largely depends on this sequence being true in most of the cases.

\section{References}

1. Al-Jasser NM, Bello LL. Time of eruption of primary dentition in Saudi children. J Contemp Dent Pract 2003;15(3):65-75. DOI: 10.5005/jcdp4-3-65.
2. Shourie KL. Eruption age of the teeth in India. Indian J Med Res 1946;34:105-118.

3. Kaul S, Saini S, Saxena B. Emergence of permanent teeth in school children in Chandigarh, India. Arch Oral Biol 1975;20(9):587-593. DOI: 10.1016/0003-9969(75)90079-5.

4. Amrit T, Chawla HS. Norms of eruption of permanent teeth among the children of Chandigarh. Ann Hum Biol 1978;192:2-6.

5. Pahkala R, Pahkala A, Laine T. Eruption pattern of permanent teeth in a rural community in Northeastern Finland. Acta Odont Scand 1991;49(6):3419. DOI: 10.3109/00016359109005930.

6. Willems G, Van Olmen A, Spiessens B, et al. Dental age estimation in belgian children: Demirjian's technique revisited. J Forensic Sci 2001;46(4):893-895. DOI: 10.1520/JFS15064J.

7. Logan WHG, Kronfeld R. Development of the human jaws and surrouding structures from birth to the age of fifteen years. J Am Dent Assoc 1933;20(3):379-428.

8. Dahlberg AA, Menegaz-Bock RM. Emergence of the permanent teeth in Pima Indian children: a critical analysis of method and an estimate of population parameters. J Dent Res 1958;37(6):1123-1140.

9. Mc Call JO, Wald SS. Clinical dental roentgenology: technic and interpretation including roentgen studies of the child and young adult. Philadelphia: WB Saunders; 1940.

10. Khan N. Eruption time of permanent teeth in Pakistani children. Iranian J Publ Health 2011;40(4):63-73. 
11. Lakshmappa A, Guledgud MV, Patil K. Eruption times and patterns of permanent teeth in school children of India. Indian J Dent Res 2011;22(6):755-763. DOI: 10.4103/0970-9290.94568.

12. Moshkelgosha V, Khosravifard N, Golkari A. Tooth eruption sequence and dental crowding: a case-control study. F1000Res 2014;3:122. DOI: 10.12688/f1000research.3196.1.

13. Poureslami H, Asl Aminabadi N, Sighari Deljavan A, et al. Does timing of eruption in first primary tooth correlate with that of first permanent tooth? A 9-years cohort study. J Dent Res Dent Clin Dent Prospects 2015;9(2):79-85. DOI: 10.15171/joddd.2015.0016.

14. Krishnan B, Liza John. A. Cross-sectional study of eruption pattern of teeth in 10-12 years old children. J Evolut Med Dent Sci 2015;4(42):7381-7386. DOI: 10.4103/2249-4863.154670.

15. Cecere S, Leroy R, Groenen PJ, et al. Estimating emergence sequences of permanent teeth in flemish school children using intervalcensored biplots: a graphical display of tooth emergence sequences. Community Dent Oral Epidemiol 2012;40(Suppl 1):49-55. DOI: 10.1111/j.1600-0528.2011.00666.x.

16. Hoffding J, Maeda M, Yamaguchi K, et al. Emergence of permanent teeth and onset of dental stages in Japanese children. Community Dent Oral Epidemiol 1984;12(1):55-58. DOI: 10.1111/j.1600-0528.1984. tb01411.x.

17. Magnusson TE. Emergence of permanent teeth and onset of dental stages in the population of Iceland. Community Dent Oral Epidemiol 1976;4(1):30-37. DOI: 10.1111/j.1600-0528.1976.tb00966.x.

18. Savara BS, Steen JC. Timing and sequence of eruption of permanent teeth in a longitudinal sample of children from Oregon. JADA 1978;99(2):209-214. DOI: 10.14219/jada.archive.1978.0277.

19. Lee MM, Low WD, Chang KS. Eruption of the permanent dentition of southern Chinese children in Hong Kong. Arch Oral Biol 1965;10(6):849-861. DOI: 10.1016/0003-9969(65)90078-6.

20. Knott VB, Meredith HV. Statistics on eruption of the permanent dentition from serial data for North American white children.
Angle Orthod 1966;36(1):68-79. DOI: 10.1043/0003-3219(1966)0362. $0 . \mathrm{CO} ; 2$.

21. Vincent K, Probit Analysis. Available http://userwww.sfsu.edu/ efc/ classes/biol710/probit/ProbitAnalysis.pdf [Last from: cited 2010 on Jan 2].

22. Heidmann J. Comparison of different methods for estimating human tooth-eruption time on one set of Danish national data. Archives of Oral Biology 1986;31(12):815-817.

23. Demirjian A, Goldstein H, Tanner JM. A new system of dental age assessment. Hum Biol 1973;45(2):211-217.

24. Bhanat S, Patel D. Dental \& skeletal maturity indicators of chronological age: radiographic evaluation amongst children in Gujarat, India. IOSR J Dent Med Sci 2013;6(4):6-12. DOI: 10.9790/08530640612.

25. Nolla C. The development of the permanent teeth. ASDC J Dent Child 1960;27:254e66.

26. Haavikko K. The formation and the alveolar and clinical eruption of the permanent teeth. An orthopantomographic study. Suom Hammaslaak Toim 1970;66(3):103-170.

27. Mallick S, Imranulla M, Naveen Kumar PG, et al. Assessment of malocclusion status in 15 year old school children of a South Indian city - a cross-sectional survey. IJBR 2017;8(01):26-32.

28. Raina $R$, et al. Assessment of malocclusion and orthodontic treatment needs among 13-15 year old school going children of Bengaluru North: a cross-sectional study. IJOCR 2017;5(2):105-112.

29. Tak M, Nagarajappa R, Sharda AJ, et al. Prevalence of malocclusion and orthodontic treatment needs among 12-15 years old school children of Udaipur, India. Eur J Dent 2013;7(Suppl 1):S45-S53. DOI: 10.4103/1305-7456.119071.

30. Shivkumar KM, Chandu GN, Shafiulla MD. Severity of malocclusion and orthodontic treatment needs among 12-15 year old school children of Davangere district, Karnataka, India. Eur J Dent 2010;4(3):298-307. DOI: 10.1055/s-0039-1697843. 